\title{
Política e experimentalismo em Ana Hatherly
}

\author{
Maria da Glória Bordini ${ }^{1}$
}

Universidade Federal do Rio Grande do Sul

\begin{abstract}
RESUMO: EM 2008 COMEMORAM-SE OS CINQÜENTA ANOS DE PRODUÇÃO POÉTICA DE ANA HATHERLY, CUJA MARCA MAIS SALIENTE É A PROVOCAÇÃO DO STATUS QUO. ESTE ENSAIO ACOMPANHA O DESENVOLVIMENTO DE SUA OBRA, FOCALIZANDO EM ESPECIAL UM CALCULADOR DE IMPROBABILIDADES (2001).

ABSTRACT: 2008 CELEBRATES FIFTY YEARS OF POETIC PRODUCTION BY ANA HATHERLY, WHOSE MOST PROMINENT MARK IS THE PROVOCATION OF THE STATUS QUO. THIS ESSAY FOLLOWS THE DEVELOPMENT OF HER BODY OF WORK FOCUSING ESPECIALLY ON UM CALCULADOR DE IMPROBABILIDADES (2001).
\end{abstract}

PALAVRAS-CHAVE: ANA HATHERLY - POESIA EXPERIMENTAL - CONCRETISMO - ENGAJAMENTO POLÍTICO

KEY-WORDS: ANA HATHERLY - EXPERIMENTAL POETRY - CONCRETE POETRY - POLITICAL COMMITTMENT

\footnotetext{
1 Professora colaboradora convidada do Programa de Pós-graduação em Letras da UFRGS. Ex-professora titular de Teoria da Literatura da PUCRS. Pesquisadora 1B do CNPq.
} 
s relações entre a poesia moderna e as questões políticas caracterizam-se pela tensão, desde os simbolistas Baudelaire ou Verlaine. O lançamento, em 1857, de As flores do mal, em que se fundiam o alto e o baixo, o eterno e o instante, leva o autor a ser acusado de ultrajar a moral pública. Verlaine, por sua vez, em 1873, é perseguido pela polícia por haver participado da Comuna de Paris, ativismo a que se une uma vida desregrada, criminosa, inclusive, mas poeticamente regida pela "música, acima de tudo". Subjetividades inovadoras, desafinadas com o estatuto burguês dominante, os inúmeros nomes das vanguardas européias do início do século XX, sejam futuristas, dadaístas ou surrealistas, assim como os modernistas brasileiros, valem-se da ruptura com a mímese e da primazia à inventividade para manifestar seu descontentamento com os rumos do projeto moderno do capitalismo industrial. Mesmo quando admiram a ciência e a técnica, não deixam de dissolver a sua raiz racionalista em experimentos que se valem de tudo o que não é racional, como o sonho, o ilogismo, a desestruturação das formas conhecidas. A produção da "forma difícil", como percebeu Theodor Adorno $^{2}$, não era apenas "arte pela arte", pois dificultar, fechar-se no formalismo, valorizar a expressão e banir a representação significava também um gesto de recusa social, um atentado aos poderes constituídos. Não é sem motivo - ou apoliticamente - que as vanguardas cercaram-se de manifestos programáticos, delimitando seus objetivos e técnicas, num esforço claro de informar o público, de formá-lo para o novo, para o inusitado, para a contestação.

A lição das vanguardas é retomada em meados do século XX, com os movimentos das artes plásticas e da poesia, bem como da música, que se organizam em torno da idéia da concretitude. Já nos anos 30, na Europa, pensava-se, à maneira de Mondrian, em geometrizar o mundo, ignorando as formas da natureza. ${ }^{3}$ Nos anos 50 , a poesia segue essa vereda desprezando a ilusão representativa do discurso poético, por meio da extinção do verso e da

\footnotetext{
2 Diz Adorno: "Na libertação da forma, tal como a deseja toda arte genuinamente nova, cifra-se antes de tudo a libertação da sociedade, pois a forma, a coerência estética de todo o elemento particular, representa na obra de arte a relação social; eis por que o estado de coisas existente repele a forma emancipada". (ADORNO, 1970: 285).

3 À mesma época, o designer, arquiteto e escultor Max Bill, na Suíça, propunha uma arte desligada do real, matematizando as formas e construindo-as concretamente. Foi homenageado na XXIV Bienal de São Paulo de 1998, em que foram expostas peças de metal polido.

(V. < www1.uol.com.br/bienal/24bienal/nuh/enuhmonbill01.htm>)
} 
estrofe, tomando o espaço da página ou do cartaz como base para a estruturação gráfica das palavras, numa sintaxe analógica, ideogramática, que tornasse objetivados os sentidos, numa apreensão gestáltica. O movimento aparece também no Brasil e em Portugal, entronizando Mallarmé e seu Lance de dados, Ezra Pound e seus Cantos, e. e. cummings e seu XAIPE e os caligramas de Apollinaire como modelos e antecessores.

Em Portugal, assim como aconteceu no Brasil, o concretismo emerge fortalecido nos anos 60, sob um regime de exceção. Lá é concomitante com a eclosão da guerra colonial, enquanto pelo resto do mundo espalham-se os movimentos de liberação da mulher e o movimento negro, o antibelicismo, os hippies, a rebelião dos jovens, o rock, a arte pop, a par da Guerra do Vietnã, das viagens espaciais, da Guerra Fria, dos avanços tecnológicos, o que repercute sobre a ditadura salazarista no sentido de necessidade de abertura, de respeito aos direitos civis, de uma política transparente. Gestava-se aos poucos a Revolução dos Cravos, sem que os grupos experimentalistas notassem de forma mais clara a relação que se estabelecia entre sua insubordinação estética e a mudança futura.

Nesse movimento do experimentalismo português avulta o nome de Ana Hatherly ${ }^{4}$. Ela estreou na poesia portuguesa em 1958, com um livro de poemas intitulado Um ritmo perdido, publicado por conta própria em Lisboa. Em 2008 comemoram-se seus cinqüenta anos de produção poética, cuja marca mais saliente é a provocação do status quo. A história editorial da autora de Um calculador de improbabilidades (2001) é de luta ingente pela ruptura de paradigmas da herança lírica portuguesa, tendo em mira a experimentação dos limites da linguagem e da forma poemática. Ela começa por violar a linearidade do verso e rearranjar o poema espacialmente, inserindo-se nas correntes concretistas dos anos 60. Antes, porém, já ousara criar o libretto de um balé, La danse de l’Oubli, merecedor dos elogios de Serge Litor, então diretor da Ópera de Paris.

4 Ana Hatherly (Porto, 1929), além de poeta, ensaísta, tradutora, artista plástica e cineasta, é doutora em Estudos Hispânicos pela Universidade da Califórnia em Berkeley e leciona como catedrática na Universidade Nova de Lisboa. Várias vezes premiada em Portugal, recebeu em 2003 o Prêmio de Poesia Evelyne Encelot, na França, e o Prêmio Hannibal Lucic, na Croácia. Sua obra poética está presente em antologias e histórias da literatura contemporânea de Portugal e do Brasil, e é conhecida em outros países cuja língua não é o português, como a Espanha, a Inglaterra, a Alemanha, a Holanda, a Dinamarca, a Suécia, a República Checa e os Estados Unidos. 
Em Sigma (de 1965), os textos em verso e em prosa ressoam as odes de Alberto Caieiro e algo mais de Fernando Pessoa, mas como objeto de experimento quase cibernético, impregnado de uma sensualidade maquinal, de que o poema "O Poeta é um calculador de improbabilidades" é exemplo dos mais significativos. Dos 41 versos que o constituem, os seguintes fornecem uma idéia do programa poético da autora, pois a escolha do título desse poema para a antologia de sua obra indica vertentes que ela seguiria em sua carreira:

O poeta é

um calculador de improbabilidades limita

a informação quantitativa fornecendo

reforçada informação estésica.

É uma máquina eta-erótica em que as discrepâncias

são a fulgurância da máquina.

A psicologia do maquinal sabe que basta

que se crie um pólo positivo para que o pólo

negativo surja

ou vice-versa

O maquinal eta-erótico é tu-eu.

O maquinal tu-eu

cuja tarefa árdua não é

definir a verdade está no meio da profusão

dos objectos

e considera o consumo a verdade deslocada

deslocação de grande tonelagem

laboriosa alfaiataria de eros

constante moribunda

e esse opróbrio dispersivo e vexável

indifere a vida esponjosa.

A história agrega a dificuldade essencial

das variáveis e o ensejo das coisas

prática difícil

está para o maquinal como uma indústria apócrifa. (HATHERLY, 2001: 60-1) 
Por menos que o projeto aqui poetizado seja intencional - e intencionalidade é uma palavra especialmente adequada para descrever a poesia de Hatherly -, percebem-se nesse texto alguns termos-chave de sua prática: o trabalho poético como cálculo, o improvável da poesia, o dualismo informação científica/ deformação estética, a discrepância, o desvio como fulguração, a máquina produtora de repetição, a insistência no uso da letra grega "eta" como elemento compositivo (sugerindo talvez o ETA, movimento de libertação dos bascos), o par erótico tu-eu - cuja sonoridade lembra o verbo francês tuer, matar - buscador da "verdade deslocada", o consumo, e seu fornecedor, a história com sua imprevisibilidade.

Em Operação 2 (de 1967), de início proposto como uma revista de teoria e prática do experimentalismo então florescente em Portugal, tem-se um livro de ensaios-poemas, interessado em testar as potencialidades abertas pelo estruturalismo francês para as estruturas poéticas. Nesse livro, aparecem termos posteriormente nucleares na poética da autora, como "operação", com o duplo sentido de ato tecnológico e ato cirúrgico, "detergência", que ela associa a uma "vontade de limpeza" da sociedade de consumo (v. HATHERLY, 2001: 18) e "tisana", ligado à experimentação da poesia em prosa. As operações executadas vão do Tipo A ao Tipo $H$, de "deslocação semântica de uma palavra privilegiada num contexto" até "comutação de sintagma" (p. 71). Veja-se um exemplo do Tipo B, "evolução semântica acelerada de uma palavra privilegiada num contexto":

\section{A ESSÊNCIA DO DETERGENTE}

Foi quando recentemente relia um livro de Rimbaud que deparei com a surpreendente palavra detergente.[...]

Achei-me perante essa palavra detergente e verifiquei que podia desde logo decompô-la em três partes: de ter gente, deter gente e deterge ente. Mas nenhuma destas partes era detergente.

A sua detergência fundamental diluira-se criando contudo uma nova, como direi, consistência. Verifiquei então que detergente era algo consistente. Em que consistia, porém? Em sua concisão? Em sua consistência?

Detergente era algo de agente, algo de agir na gente de uma forma detergente, uma maneira de ser gente, de ter gente, de deter gente. De detergir o ente. Mas qual ente? [...] (HATHERLY, 2001: 79) 
A par do jogo verbal de aparência inconseqüente, insinuam-se semanticamente, nessa "operação" por decomposição arbitrária, aspectos que o leitor mais avisado identifica como uma proposição oculta de reivindicações sociais, um desafio ambíguo aos que detêm gente.

Em outros livros posteriores, como Eros frenético (1968), 39 Tisanas (1969) e Anagramático (1970), Ana Hatherly se volta para o passado português e emprega, sempre em clave experimentalista, formas próprias da música, da pintura e da poesia barrocas. Eros frenético opera segundo a técnica do tema e variações. Os poemas são longos, discursivos, encadeados em ritmo alucinatório, prenhes de uma terminologia erótico-anatômica. Suas "Tisanas" - ao longo de sua produção ela compõe várias séries dessa experimentação discursivo-poética - são, como ela mesma diz, uma proposta que contraria os seus pares: "Enquanto os meus colegas propõem soluções eu proponho infusões: TISANAS! É que não sendo um romântico sou todavia um químico". ("A poesia tem sido uma arte verdadeiramente animal", p. 175.) Nelas começa a transparecer, com maior evidência, o aspecto lúdico-satírico que identifica igualmente sua obra, ao lado de uma adesão à racionalidade, ao pensar criativo, que não teme separar, rearranjar, correlacionar, misturar, como nos processos experimentais da ciência.

Em Anagramático (de 1970), o experimentalismo de Hatherly se exaspera. A obra se divide em quatro Livros, I - A maldade semântica; II - A detergência morosa; III - Leonorana; IV - Meta-leitura. Baseada no princípio do anagrama, que ela estudou nos clássicos e também em Saussure e Benveniste, a poeta produz o que chama de uma antigramática, uma poética negativa, de alto teor provocativo, pois a associa ao próprio nome Ana. Essa atitude de expor ou reivindicar a autoria sem falsos pudores provoca uma polêmica no Diário de Lisboa do dia 12 de novembro de 1970, em que uma crítica de Nelson de Matos a acusa de des-semantizar a linguagem e utilizar mal a noção de arbitrariedade do signo. O texto acaba com o seguinte veredicto:

Por tudo isso ANAGRAMÁTICO é livro cheio de incorreções ou de uma informação mal entendida. Por tudo isso também uma aventura que a autora pretende apresentar como revolucionária sob o ponto de vista poético acaba, fatalmente, por deixar bem expressa a sua gratuitidade. (HATHERLY, 2001: 374) 
A essa posição dura, a autora responde no mesmo Diário, no dia 9 de dezembro de 1970:

Se toda a arte se baseia num formulário, e cada autor usa um formulário, residindo o seu 'talento criador', o seu 'génio', no modo como ele actuar em relação a esses processos (como os manipular, alterar, transformar, desfigurar, recriar), actualmente interessa-me sobretudo o momento em que um autor, utilizando um formulário, pela sua intervenção criadora o inutiliza.[...] Creio na eficácia do rigor e nas limitações (relativas) de princípio que o autor determina para cada obra que realiza. Sempre assim se tem procedido, de resto; sempre o autor nos surge como o laborioso construtor do equilíbrio das dificuldades (que lhe são impostas pelas leis do 'ofício') e sempre só momentaneamente vitorioso delas. O momento artístico privilegiado será esse em que um autor, superando as dificuldades de uma arte que é a todo o momento um desafio, se ultrapassa a si mesmo. ${ }^{5}$

Está em jogo, nessa disputa, a antinomia entre a tradição da lírica moderna e a poesia experimentalista dos anos 60-70. Portugal possuía - e possui - uma plêiade de excelentes poetas líricos, altamente inventivos e capazes de lançar luz sobre complexidades pessoais e sociais das mais intrincadas. Não que estivessem acomodados nas formas fixas ou academicistas - eram e são desconstrutores das noções correntes de verso e poema. Acontece que os concretistas haviam irrompido como um grupo que parecia abandonar a palavra enquanto signo verbal para torná-la uma objetividade visual. Essa violação do cerne da tradição lírica, fundada na sonoridade, no ritmo, na semantização de todas as estruturas lingüísticas, era tão chocante que o continuado experimentalismo, praticado não apenas por Hatherly, mas também por E. M. de Melo e Castro, Alberto Pimenta e Fernando Aguiar, entre outros, lidando com a visualidade, depois com os videogramas, as performances, os pixels da tela do computador, aparecia como mero diletantismo de um grupo que espetacularizava a si mesmo com fervor.

É contra o preconceito de que a experimentação formal é puro vácuo que Hatherly se insurge. Seu radicalismo, nessa época, traz implícito um ousado

5 V. réplica citada na íntegra, idem, p. 375. 
descontentamento com o establishment, que, como se sabe, em Portugal, estava sob o domínio de uma ditadura cujo poder censório era desmedido. Assim como no Brasil ocorreu com os irmãos Haroldo e Augusto de Campos, a poesia que se produz como constante experiência com a palavra, trabalhando-a em dimensões não-vocais, com apoio teórico sofisticado, é vista como elitismo despreocupado com as aflições contemporâneas. Lá, como aqui, a renovação do ar que o experimentalismo produziu foi minimizada pelos eventos históricos relacionados com as respectivas aberturas políticas. Em Portugal, talvez mais do que no Brasil, os ares renovados trazidos pela poesia experimental foram inspirados melhor pelos demais poetas, o que qualificou a poesia contemporânea portuguesa para acima de qualquer média.

De certo modo, quando ocorre o 25 de Abril, a poesia de Hatherly gradualmente se transforma, assim como a sociedade portuguesa o faz. Não se trata de um rompimento abrupto com os modos de antes, mas de uma transição insensível para outras condutas, agora que as liberdades fundamentais estavam garantidas. No caso da poeta, ela deixa para trás o radicalismo formal e, como depõe, passa a "desenvolver mais a vertente do poema em prosa, praticado nas Tisanas, e a vertente da Poesia Visual na sua relação com a escrita chinesa arcaica e com a produção barroca" (p. 22).

A autora se apropria da estética barroca, com seus jogos de idéias e paradoxos, com seu conceptismo, mas numa atitude pós-moderna de citação e parodismo. Em Poesia 1958-1978, ela apresenta poemas em duas colunas, sendo a primeira de citações de pensadores e a segunda de versos líricos, paralelizando razão e emoção. Em O cisne intacto (de 1981), obra que ela considera "um ponto culminante na minha produção poética - um ponto de maturidade, de domínio da forma e da expressão que só foi possível atingir depois de mais de 20 anos de actividade experimental" (p. 24), os poemas se modificam. Deixam de ser discursivos para se tornarem sintéticos, reflexivos, cercados de silêncios, mas de teor não menos hermético, embora, à primeira vista, mais aberto. O tema de cada primeiro verso é o mote para o poema seguinte, num encadeamento que se desdobra em momentos de iluminação, de erotismo, de metapoética, mas igualmente de citação e de glosas. Vejam-se os poemas-estrofes a seguir: 
tudo arrasar

$$
\text { na página }
$$

delucidar

na folha

oh versátil demanda

que espumas exige o teu sarcasmo!

a medida é esplêndida

a vitória

c

1

a

1

a

$\mathrm{m}$

e

$\mathrm{n}$

$\mathrm{t}$

e

o calmo acalmado pulsar

a pujança pujante seminal

$$
\begin{aligned}
& \text { do dar-se } \\
& \text { do negar-se } \\
& \text { do tragar-se }
\end{aligned}
$$

o genitor de imagens

necessita

o

do

fundo sêmico exílio 
passando

passando

pensando

pensando

(HATHERLY, 1981)

Aqui, observa-se a conjunção magistral do legado concretista com um retorno ao verso, não ao tradicional, mas ao verso livre moderno. A disposição gráfica no primeiro fragmento aproveita habilmente o espaço em branco, para sugerir, no silêncio, diversas tomadas de atitude interpretativa ao leitor. Os versos "na página", "na folha" são paralelísticos, o pronome "tudo" comanda a primeira estrofe e põe em paralelo também os verbos "arrasar" e "delucidar", conferindo à tarefa do poeta, figura ali oculta, a obrigação simétrica da crítica, da destruição e da iluminação. Na segunda estrofe, em tom exclamativo, esse ofício é aclarado com o termo "sarcasmo", amenizado por "espumas", o que, além da aliteração com "versátil" e "sarcasmo", aproximando-as semanticamente, pode gerar a imagem de boca espumante, raivosa. A última estrofe é irônica. Paraleliza "medida" e "vitória", interpondo "esplêndida" entre as duas, como adjetivo, mas o êxito do poeta logo é afirmado e desmentido com a linha oblíqua - como todo o texto, no plano do sentido - em que se lê "clara mente".

$\mathrm{O}$ texto imediatamente seguinte retoma o mote, ou seja, a tarefa do poeta, com a inversão da atitude de irado para calmo. O "calmo acalmado" órgão pulsante equivale a "pujança" no segundo verso, em que aliterativamente se liga a potência e, por contraste, a inseminação. O sujeito "pujança", na segunda estrofe, recebe os atributos da doação, da negação e da autodevoração, postos em paralelismo simétrico, o que os justapõe. $\mathrm{Na}$ terceira estrofe, os sujeitos "pulsar" e "pujança" se reúnem, por processo metonímico, a seu todo, "o genitor de imagens". Num anacoluto, o predicado do sujeito "genitor", "necessita o exílio" é interrompido, outra vez obliquamente, pelos versos "o", "do" e "fundo sêmico". A estrofe determina, pois, ao poeta, um separar-se do sentido, sem de fato permiti-lo, pois o verso final dela é "fundo sêmico exílio". As duas outras estrofes, que finalizam o texto, repetem os gerúndios "passando" e "pensando", em blocos deslocados, de modo que o 
"exílio" se compõe de passagem e pensamento, os dois movimentos-chave da poética de Hatherly.

Em Joyciana (de 1982), obra coletiva, ou em Rilkeana (de 1999), que mereceu o Prêmio de Poesia do PEN Club português, a poeta põe em prática uma revisão do experimentalismo dos anos 60-70, em que predomina um ludismo virtuosista, mas sem qualquer conotação alienante, trabalhando motes retirados de Joyce e de Rilke e glosados por meio de variações. Nessas obras mais recentes, o malabarismo com as citações, tão característico da poesia pósmoderna, sempre lhes ultrapassa o sentido original, gerando novos, por vezes com inflexões líricas, ou metafísicas ou metapoéticas sui generis. Observe-se esta passagem de Joyciana, glosando o famoso fragmento de Finnegan's wake, "riverrun" (p. 359):
$\mathrm{O}$
rio
corrio
corri-o
corri'o
co'rio
rioocorre
riocorre
riocor
riomor
rioamor
rivermore
rivercuor
ribacor
rivercore
riverpour
riverfour
riverfor

evermore

eva mor

evaamor 
O laborioso desdobramento da palavra "river", "rio" em português, separado do verbo "run", "correr", igualmente flexionado, cria um poema amoroso, inserindo as palavras "cuore", "cor", para "coração" e lexemas relativos ao fluxo. Um dos compostos é "amor" e leva, por citação implícita, ao poema de Poe, "The raven", cujo refrão é "nevermore" , "nunca mais", mas invertido para "evermore", "sempre" e deslocado para a mulher primordial, Eva. Com esses procedimentos variacionais, Hatherly obtém um lírico poema amoroso, numa forma que, na superfície, parece mero jogo fútil com palavras. Preservando a sonoridade joyceana da corrida do rio, Hatherly retorna à encantatória cantiga de amor do medievo português, pela mediação de Poe, e materializa na forma estreitada da primeira estrofe, na ondulada da segunda e no remanso da terceira, tanto a objetualidade do rio quanto a historicidade do tema amoroso.

O traçado da produção poética de Ana Hatherly se desenvolve como uma parábola. De um ponto inicial preso aos programas do concretismo, ela alça vôo na experimentação radical, em contínuas metamorfoses de estruturas poéticas tradicionais e vanguardistas, até atingir um ápice: o domínio da forma tão despregada da tradição que pode a ela retornar, sem renunciar ao experimento. Desse ponto culminante a poeta declina para o livre emprego de um saber poético penosamente adquirido, e passa ao gozo do divertissement com outros grandes poetas, num diálogo em tudo outra vez inovador. Poder-se-ia, com as devidas reservas, aproximar a poesia de Hatherly à de Francis Ponge, ${ }^{6}$ não só no poema em prosa, quando tenta obsessivamente capturar um objeto em si mesmo, sem interferência das idealizações do eu-lírico, para instituir o multiperspectivismo como modo de relação com as coisas, mas também nos exercícios intertextuais, evidenciando uma preocupação com a materialidade da palavra, com seus registros impressos, com uma historicidade que ultrapassa fronteiras nacionais e se nutre tanto do passado quanto do presente, incorporando-os ao tecido do poema.

Nessa trajetória de quase cinqüenta anos de poesia, Ana Hatherly se expõe à derrisão dos que rejeitam o novo, mantém com serenidade e apoio teórico incansavelmente estudado seus posicionamentos estéticos, reformulando-os ao ritmo das mudanças que seu país - e o mundo - atravessa. Sua poesia

V. COELHO, Marcelo. Poesia e matéria [Ponge]. In: NOVAES, p. 398-418. 
pode parecer, à vista desarmada, o exercício diletante da "arte pela arte", mas as motivações de sua inquietação artística estão profundamente radicadas no solo de seu país. Ela experimenta, por "infusões", o que pode ser politicamente mudado: primeiro pelo ataque da forma, como avant-garde que é, causando espanto e aversão, depois pelo ensinamento da percepção, quando propõe a seus leitores poemas menos concretos, mas muito mais indeterminados e carregados de supostos, incentivando a reflexão. Depois, quando a liberdade política é restaurada, ela se permite o puro jogo com seus pares, numa espécie de dança triunfal. Assim, educando o olhar para o desvio, para o não-conformismo, para a fusão entre raciocínio, intuição e emoção, o experimentalismo se faz político, sem estetizar a política.

\section{Referências Bibliográficas}

ADORNO, Theodor. Teoria estética. Lisboa: Ed. 70, 1970.

BILL, Max. Unidade tripartida. XXIV Bienal de São Paulo, 1998. Disponível em: <www1. uol.com.br/bienal/24bienal/nuh/enuhmonbill01.htm>. Acesso em 29/8/2007.

HATHERLY, Ana. Um calculador de improbabilidades. Coimbra: Quimera, 2001.

NOVAES, Adauto (Org.). Poetas que pensaram o mundo. São Paulo: Companhia das Letras, 2005. 